Cite this article as: Goyal, R., Kumar, P., 2013. Indoor-outdoor concentrations of particulate matter in nine microenvironments of a mix-use commercial building in megacity Delhi. Air Quality, Atmosphere and Health 6, 747-757. http://dx.doi.org/10.1007/s11869-013-0212-0

\title{
Indoor-outdoor concentrations of particulate matter in nine microenvironments of a mix-use commercial building in megacity Delhi
}

\author{
Radha Goyal ${ }^{\mathrm{a}}$ and Prashant Kumar ${ }^{\mathrm{b}, \mathrm{c},}$ *
}

${ }^{a}$ CSIR-NEERI, Delhi Zonal Laboratory, Naraina Industrial Area, Delhi-110028, India

${ }^{\mathrm{b}}$ Department of Civil and Environmental Engineering, Faculty of Engineering and Physical Sciences (FEPS), University of Surrey, Guildford GU2 7XH, United Kingdom

${ }^{\mathrm{c}}$ Environmental Flow (EnFlo) Research Centre, FEPS, University of Surrey, Guildford GU2 7XH, United Kingdom

\begin{abstract}
Three naturally and six mechanically ventilated microenvironments (MEs) of a mixed use commercial building in Delhi are used to study indoor-outdoor $(I / O)$ relationships of particulate matter $\leq 10 \mu \mathrm{m}\left(\mathrm{PM}_{10}\right), \leq 2.5 \mu \mathrm{m}\left(\mathrm{PM}_{2.5}\right)$ and $\leq 1 \mu \mathrm{m}\left(\mathrm{PM}_{1}\right)$. Effect of environmental and occupancy parameters on the concentrations of PM during working and non-working hours (i.e. activity and non-activity periods, respectively) are also investigated. Average outdoor concentration of $\mathrm{PM}_{10}$ and $\mathrm{PM}_{2.5}$ were found to exceed the 24 hour averaged national standard values, showing a polluted environment surrounding the studied building. During the working hours, indoor $\mathrm{PM}_{10}$ concentration was found 6-10 times, both $\mathrm{PM}_{2.5}$ and $\mathrm{PM}_{1}$ were 1.5-2 times, higher than the non-working hours in the selected MEs. The variations of indoor concentrations were highest $\left(17.1-601.2 \mu \mathrm{g} / \mathrm{m}^{3}\right)$ for $\mathrm{PM}_{10}$ compared with $\mathrm{PM}_{2.5}\left(16.9-102.6 \mu \mathrm{g} / \mathrm{m}^{3}\right)$ and $\mathrm{PM}_{1.0}\left(10.6-63.6 \mu \mathrm{g} / \mathrm{m}^{3}\right)$. The $I / O$ for $\mathrm{PM}_{10}, \mathrm{PM}_{2.5}$ and $\mathrm{PM}_{1.0}$ varied from 0.37-3.1, 0.2-3.2 and 0.17-2.9, respectively. The results suggest highest $I / O$ for $\mathrm{PM}_{10}, \mathrm{PM}_{2.5}$ and $\mathrm{PM}_{1}$ as 3.1, 2.15 and 1.76, respectively, in all the three natural ventilated MEs (canteen, kitchen, reception). Irrespective of PM types, the average $I / O$ was $<1$ for mechanically ventilated MEs compared with $>1$ for naturally ventilated MEs. As opposed to $\mathrm{PM}_{1}$, better correlation ( $\mathrm{r}>0.6$ ) was noted between indoor $\mathrm{PM}_{10}, \mathrm{PM}_{2.5}$ and $\mathrm{CO}_{2}$ concentrations in most of the airtight MEs.
\end{abstract}

Key words: Particulate Matter; Building microenvironment; Environmental comfort parameters; Occupancy; I/O relationship; Megacity Delhi

*Corresponding author. Tel.: +44 1483 682762; fax: +44 1483 682135; E-mail addresses: P.Kumar@surrey.ac.uk (Prashant Kumar); radhagoyal@gmail.com (Radha Goyal) 
Cite this article as: Goyal, R., Kumar, P., 2013. Indoor-outdoor concentrations of particulate matter in nine microenvironments of a mix-use commercial building in megacity Delhi. Air Quality, Atmosphere and Health 6, 747-757. http://dx.doi.org/10.1007/s11869-013-0212-0

\section{Introduction}

Indoor particulate matter $(\mathrm{PM})$ is often linked with detrimental health impacts. Fractions of the $\mathrm{PM}$ (i.e. $\mathrm{PM}_{10}, \mathrm{PM}_{2.5}$ and $\mathrm{PM}_{1}$; the subscript indicating the upper cut-off particle diameter in $\mu \mathrm{m}$ ) contains a complex mixture of solid and liquid particles that are made of both organic and inorganic substances (Heal et al. 2012). The size of the particles is vital for determining the duration for which the particles remain suspended in air for human exposure. $\mathrm{PM}_{1}$ has not been studied enough yet to accumulate sufficient knowledge to regulate this size fraction, but there are evidences that these small particles cause adverse health effects (Polichetti et al., 2009; Heal et al., 2012). On the other hand, $\mathrm{PM}_{10}$ and $\mathrm{PM}_{2.5}$ have already been established as a cause for premature mortality and morbidity. For instance, Pope III and Dockery (2006) estimated a mortality increase in the order of 4-6\% with the increase in $\mathrm{PM}_{10}$ and $\mathrm{PM}_{2.5}$ concentrations by $20 \mu \mathrm{g} / \mathrm{m}^{3}$ and $10 \mu \mathrm{g} / \mathrm{m}^{3}$, respectively, in the ambient air of US cities.

Indoor activities such as walking, sweeping, and floor cleaning cause the generation of particles over $1 \mu \mathrm{m}$ size, due to their resuspension from the dust deposited on floors and other interior surfaces (Thatcher and Layton 1995; Luoma and Batterman 2001). In particular, $\mathrm{PM}_{2.5}$ and $\mathrm{PM}_{1}$ are generated in substantial amounts during activities such as cooking (Morawska et al. 2003; Kumar et al. 2013a), heating and wood burning in fire places (Kleeman et al. 1999; Hussein et al. 2006; Hussein et al. 2005), and tobacco smoking (Kleeman et al. 1999; Ott and Siegmann 2006; Miller and Nazaroff 2001).

Indoor air is also affected by outdoor air through infiltration (Colbeck et al. 2010; Massey et al. 2009; Chen et al., 2012). As a result, the geographical hetrogenitiy in indoor PM exposure can be expected due to inter-city differences in PM concentrations (Zhou et al., 2013). In the absence of indoor sources, the indoor $\mathrm{PM}_{10}, \mathrm{PM}_{2.5}$ and $\mathrm{PM}_{1.0}$ concentrations may show similar trends to those found in outdoor environments in naturally ventilated buildings, and can be estimated from the outdoor concentrations (Jones et al. 2000; Kumar and Morawska 2013). Therefore, indoor-outdoor $(I / O)$ relationships are important to understand the real status of indoor air quality (IAQ). However, the case becomes complex in the presence of indoor sources (e.g. cooking, cigarette smoking and sweeping) that can raise the indoor concentrations to notable levels (Morawska et al. 2001). The $I / O$ relationship in residential buildings with the indoor sources have been found to be up to 2 or even higher in certain situations (Baek et al. 1997; Wallace 1996). One of the key factors that derives the indoor concentration levels is the atmospheric dispersion of pollutants around buildings (Santos et al. 2011), which, in turn, is affected by the land use pattern of the area where a building in question is located (Kumar et al. 2013b).

Ventilation in naturally and mechanically ventilated buildings is another important parameter (Yamamoto et al. 2010). Air flow rate and its patterns are the two key indicator parameters for ventilation effectiveness in buildings. Higher ventilation flow rates generally result in lower average pollutant concentration. In a well-mixed condition, the average pollutant concentration will reduce linearly with the increase in ventilation flow rate (Memarzadeh 2009). Similarly, the air flow pattern inside the building is the driving force for building design and orientation to have effective ventilation. Several studies have reported the links between the IAQ and air flow rates in indoor environments by analyzing naturally and mechanically ventilated systems as well as the relation between indoor and outdoor air quality. For instance, Kukadia and Palmer (1998) studied the influence of atmospheric pollution on indoor pollution levels in two (naturally ventilated and air 
Cite this article as: Goyal, R., Kumar, P., 2013. Indoor-outdoor concentrations of particulate matter in nine microenvironments of a mix-use commercial building in megacity Delhi. Air Quality, Atmosphere and Health 6, 747-757. http://dx.doi.org/10.1007/s11869-013-0212-0

conditioned) buildings in the UK. They found that infiltration of outdoor pollution is higher in naturally ventilated buildings compared with air conditioned buildings. Chaloulakou et al. (2003) studied the influence of outdoor CO concentration on the indoor $\mathrm{CO}$ concentration in two different naturally ventilated indoor environments (i.e. an office and a public school) in Athens, Greece. They concluded that outdoor concentrations can be used as a good estimator for indoor concentrations in naturally ventilated buildings. The $I / O$ for office building was higher (0.74 to 1.0$)$ than those for school building (0.53 to 0.89). The difference was attributed to factors such as variation in meteorological conditions, different dimensions, layout and orientation of the buildings. Goyal and Khare (2009) studied the influence of outdoor $\mathrm{PM}_{10}, \mathrm{PM}_{2.5}$ and $\mathrm{PM}_{1.0}$ concentrations on the indoor classrooms concentrations of a naturally ventilated school building in Delhi, India. They concluded that the environmental parameters (temperature, relative humidity, wind speed and direction) and ventilation rate in building significantly influence the $I / O$ of $\mathrm{PM}_{2.5}$ and $\mathrm{PM}_{1.0}$. They also noted a strong influence of the occupant's activities on the $I / O$ of $\mathrm{PM}_{10}$ in the classrooms. More recently, Habil et al. (2013) studied the $I / O$ ratios of various PM fractions for the roadside and residentially located schools of Agra City in India. They found the highest $I / O$ ratios during the summer season up to 1.31 $\left(\mathrm{PM}_{10}\right), 1.20\left(\mathrm{PM}_{2.5}\right)$ and $1.25\left(\mathrm{PM}_{1}\right)$ for the residentail schools, and up to $1.22\left(\mathrm{PM}_{10}\right), 1.19$ $\left(\mathrm{PM}_{2.5}\right)$ and $1.24\left(\mathrm{PM}_{1}\right)$ for the roadside schools. They attributed these highest ratios in summers to a much higher ventialtion rate, which ranged between $\sim 74$ and $100 \mathrm{~m}^{3} \mathrm{~h}^{-1}$, brought the outside polluted air indoors, and led to accumulation of PM in classrooms.

A number of previous studies have also reported the influence of various indoor sources, occupant's activities, outdoor infiltration and ventilation rate on the PM concentrations in indoor environments, as highlighted by our recent review article (Goyal et al. 2012). However, the effect of building locations on the indoor PM concentrations, especially in a mixed use commercial building environment in one of the most polluted megacities like Delhi, are not yet fully understood. This study reports the results of $\mathrm{PM}_{10}, \mathrm{PM}_{2.5}$ and $\mathrm{PM}_{1.0}$ monitoring that was carried out in nine different microenvironments (MEs) - three naturally ventilated and six mechanically ventilated - of a mixed used commercial building (see Section 2.1 for details). The aim of this study is to assess the PM levels during working (activity period) and non-working (non-activity period) hours in selected MEs during the varying level of ventilation types (natural or mechanical) and conditions (frequency of openings of doors/windows), occupants' activities, and thermal comfort parameters (temperature, pressure and relative humidity). The study also aims to assess the $I / O$ relationship of $\mathrm{PM}$ under these varying conditions during the working hours.

\section{Methodology \\ 2.1 Site description}

The study building is located at Phase-I of a mixed use (i.e. industrial and residential) Naraina Industrial Area in New Delhi (see Figure 1). The commercial activities around it involve business centres like PVR cinema, hotels, restaurants, and office buildings. The residential area surrounding the studied building is a home of $\sim 75,000$ inhabitants. A railway line carrying the diesel trains passes very close to the studied site. A slum area has also developed along the railway line and this area is a rich source of PM produced by the wood burning. The studied building is a double story with a parking zone in its basement. Ground floor is occupied by a Genomics Lab. The first floor is used by the Environmental $\mathrm{Lab}$ and the different indoor MEs at this floor are selected for the IAQ study. The MEs include a chemical lab (referred hereafter as M1), instrumentation lab (M2), microbiology 
Cite this article as: Goyal, R., Kumar, P., 2013. Indoor-outdoor concentrations of particulate matter in nine microenvironments of a mix-use commercial building in megacity Delhi. Air Quality, Atmosphere and Health 6, 747-757. http://dx.doi.org/10.1007/s11869-013-0212-0

lab (M3), computational lab (M4), two office areas including administrative office (M5), and scientist's working room (M6), reception area (M7), kitchen (M8) and canteen area (M9). Details of the volume of each ME, ventilation rates and the occupancy levels are summarized in Table 1. The floor plan of the building is shown in Figure 1b. In the chemical lab (M1), windows are kept open and the ceiling fans were continuously running to maintain the comfortable temperature during the working hours. M1 is also equipped with split type air conditioning (AC) system that was in use, but infrequently, when windows were closed and ceiling fans were switched-off. Due to the prevalence of mixed and complex nature of ventilation types, this can be considered both natural/mechanically ventilated ME. M2 to M4 are also laboratories, but are categorized as mechanically ventilated MEs, because these MEs have split type AC systems allowing exchange of outside air into these rooms. The offices (M5 and M6) are also mechanically ventilated with both split and window type ACs working in them. M7, M8 and M9 are termed as naturally ventilated MEs, where both the ceiling and exhaust fans were running for maintaining the temperature and ventilation, respectively. The outdoor air quality monitoring site was located at the terrace of the building, as shown in Figure $1 \mathrm{~b}$. The aerial distance of the ring road, which carries heavy traffic during the day time, from our ambient air monitoring locations is about 800 m (see Figure 1a).

\subsection{IAQ monitoring}

IAQ monitoring for was carried out between the month of July and August 2012. $\mathrm{PM}_{10}, \mathrm{PM}_{2.5}$ and $\mathrm{PM}_{1.0}$ measurements were made in each of the selected ME at a sampling rate of 1 minute using Environmental dust monitors (GRIMM make, Model 1.107). These PM monitors work on the principle of light scattering by drawing air with mulitple particle sizes at a sample flow rate of $1.2 \mathrm{lit} / \mathrm{min}$ through a flat laser beam produced by a laser diaode. This is capable of measuring particle mass concentrations in the $1-6500 \mu \mathrm{g} / \mathrm{m}^{3}$ range. A 15-channel pulse height analyzer for size classification detects the scattering signals in the $0.3-25 \mu \mathrm{m}$ size range. These counts from each precisely sized pulse channel are then converted to mass using well-established conversion equations (http://www.dustmonitor.com/Occupational/ 1107.htm). Two dust monitors were used for the measurements, and the sampling duration for each of the selected ME is mentioned in Table 1. One of the PM monitor was without the weather casing which was used for sequential measurements of indoor PM. The other was equipped with the weather housing, which was used for outdoor monitoring, for any possible effect of varying outdoor temperature and $\mathrm{RH}$ on particles. Concurrent sampling of both the indoor and outdoor PM could not be performed continuously for 24 hours, because of the safety constraints raised by the adjacent slum area. Outdoor air quality monitoring was therefore carried out at start and end of monitoring periods during the 09:30-17:30h (local time) and their average has been used to develop the $I / O$ relationship during the period of occupancy (Figure 2). Temperature, $\mathrm{RH}$, pressure, and $\mathrm{CO}_{2}$ were also measured simultaneously with the indoor PM monitoring at a sampling rate of one minute using an IAQ monitor (Testo make, Model X35). Occupancy levels were manually recorded at the time of monitoring in each of the MEs which are noted in Table 1.

\subsection{Data analysis}

Exploratory analysis of $\mathrm{PM}_{10}, \mathrm{PM}_{2.5}$ and $\mathrm{PM}_{1.0}$ on an hourly, 8-hourly, and 24hourly average basis was carried out, together with the meteorological parameters, to understand the influence of temporally varying environmental conditions on the PM concentrations. Indoor $\mathrm{CO}_{2}$ concentrations are monitored in all the selected MEs as a surrogate indicator of occupancy and ventilation conditions. Higher occupancy in an 
Cite this article as: Goyal, R., Kumar, P., 2013. Indoor-outdoor concentrations of particulate matter in nine microenvironments of a mix-use commercial building in megacity Delhi. Air Quality, Atmosphere and Health 6, 747-757. http://dx.doi.org/10.1007/s11869-013-0212-0

indoor space increases the $\mathrm{CO}_{2}$ concentration, resulting in reduced fresh air intake of occupants (measured as cubic feet per minute, $\mathrm{cfm}$, per person) depending on the volume of the indoor space available. Detailed description of the methodology used to estimate $\mathrm{cfm}$ is presented in SI Section S1 and the summary of results is provided in Table 1. I/O relationships of $\mathrm{PM}_{10}, \mathrm{PM}_{2.5}$ and $\mathrm{PM}_{1.0}$ have been calculated for all the selected MEs to understand the contribution from various indoor activities and the infiltration of particles from the outdoor environment. Fractional analysis of various PM sizes has also been carried out to understand the contribution of different PMs from various indoor and outdoor sources.

The SPSS package-16 has been used for performing the statistical analysis. This involved correlation and regression analysis between the pollutants and environmental parameters to understand their relationships. Pearson correlations are computed for understanding the significance of relationship between the hourly average PM concentrations and values of environmental and occupancy parameters. Difference in the mean of concentrations of $\mathrm{PM}_{10}, \mathrm{PM}_{2.5}$ and $\mathrm{PM}_{1.0}$ has been computed using the $t$-test.

\section{Results and discussion}

\subsection{Exploratory data analysis}

Figure 3 shows mean hourly concentrations of $\mathrm{PM}_{10}, \mathrm{PM}_{2.5}$ and $\mathrm{PM}_{1.0}$ as well as the environmental (temperature and $\mathrm{RH}$ ) and occupancy (indoor $\mathrm{CO}_{2}$ concentrations) parameters for all the 9 MEs. Irrespective of any ME, concentration levels of all the PM types are much higher during the working hours (09:00-18:00 h; local time) compared with non-working hours. By looking at the different PM types separately, results show that the $\mathrm{PM}_{10}$ and $\mathrm{PM}_{2.5}$ concentrations were about 6-10 and 1.5-2 times higher during working hours than those during the nonworking hours in all the MEs. Exception to the above observation was the case of M6 and M8, where $\mathrm{PM}_{10}$ was only 2-3 times higher during working hours compared with non-working hours; no significant variation in $\mathrm{PM}_{2.5}$ and $\mathrm{PM}_{1.0}$ concentrations between the two periods were observed. Large variation in $\mathrm{PM}_{10}$ concentrations can be attributed to their aerodynamic properties (e.g. higher deposition and resuspension rates) compared with $\mathrm{PM}_{2.5}$ and $\mathrm{PM}_{1.0}$ during the presence of occupants in working hours and absence in non-working hours (Thatcher and Layton 1995; Raunemaa et al. 1989). Our results are in line with the findings of a study by Blondeau et al. (2005) for eight French schools. They concluded that occupancy is the dominant source of $\mathrm{PM}_{10}$ and their activities may lead to large variations in indoor $\mathrm{PM}_{10}$ concentrations.

Inter-comparison of all the MEs indicates the maximum $\mathrm{PM}_{10}, \quad \mathrm{PM}_{2.5}$ and $\mathrm{PM}_{1.0}$ concentrations in M9, M8 and M7, respectively. The highest $\mathrm{PM}_{10}$ concentrations in M9 can be attributed to larger number of occupants and their activities compared with any other ME. Further, the highest $\mathrm{PM}_{2.5}$ concentration in M8 can be due to cooking and frying activities in the kitchen (M8). In the case of $\mathrm{PM}_{1.0}$, highest concentrations were in reception area (M7) which can be attributed to the outdoor infiltration as the large windows were mostly open during the working hours. Cigarette smoking also takes place outdoors near the windows of M7 by the office staff, which may also contribute to the penetration of outdoor $\mathrm{PM}_{1.0}$ into reception area. Among the different laboratories (M1 to M4), the highest concentrations of all the $\mathrm{PM}_{10}, \mathrm{PM}_{2.5}$ and $\mathrm{PM}_{1.0}$ were observed in M1 during both the working as well as non-working hours; this was despite the fact that there was not a great deal of difference in occupancy levels in these MEs (see Table 1). This day time increase appears to be due to the opening of windows that face towards the railway track and slum area, allowing outdoor particulates to penetrate in M1 to increase the concentration levels. During the non-working hours, the windows of M1 
Cite this article as: Goyal, R., Kumar, P., 2013. Indoor-outdoor concentrations of particulate matter in nine microenvironments of a mix-use commercial building in megacity Delhi. Air Quality, Atmosphere and Health 6, 747-757. http://dx.doi.org/10.1007/s11869-013-0212-0

were closed. This restricts both the entry and exit of PM in and out of the M1 to maintain the relatively high PM concentrations during these hours.

The $\mathrm{CO}_{2}$ concentrations analysis for all the MEs shows that the concentration in laboratory MEs (M1 to M3), reception (M7) and Kitchen (M8) varies from 350 to $450 \mathrm{ppm}$ during the day time and 250 to $300 \mathrm{ppm}$ during the night time. However, in case of M4, which is a computational lab, the $\mathrm{CO}_{2}$ concentration during day increases up to $760 \mathrm{ppm}$ at the end of working hours (1700-1800 h) and remains nearly unchanged for the next 4-5 hours, even after the end of laboratory use (Figure 3). These levels then started going down to the ambient levels to attain $\sim 300 \mathrm{ppm}$ at about $0400 \mathrm{~h}$, indicating the effect of air tightness in the laboratory (Table 1).

Indoor $\mathrm{PM}_{10}$ and $\mathrm{CO}_{2}$ concentration profiles follow a similar shape during the day and night times in the labs (M1 to M3) and office (M5 and M6). This suggests a clear relationship between indoor $\mathrm{PM}_{10}$ and $\mathrm{CO}_{2}$ concentrations, because of their release from the common sources (i.e. occupants' activities and exhalation). However, such a trend of $\mathrm{PM}_{10}$ and $\mathrm{CO}_{2}$ concentrations was not seen in case of M4, M8 and M9. For instance, the factor contributing to the higher $\mathrm{CO}_{2}$ concentration in case of M4, compared with the other MEs, was the air tightness and poor ventilation conditions. Further, more intense, though discontinuous, activities of occupants in M8 and M9 led to large but short term variations in $\mathrm{PM}_{10}$ concentration, which are not followed by increases in indoor $\mathrm{CO}_{2}$ concentrations (Goyal and Khare 2009).

Supplementary Information (SI) Table S.1 shows the 8-hourly average values of different PM types. A comparison of $\mathrm{PM}_{10}, \mathrm{PM}_{2.5}$ and $\mathrm{PM}_{1.0}$ concentrations in different lab and office MEs (M1 to M6) indicates the highest concentrations in M1 $\left(159 \pm 32.7 \mu \mathrm{g} / \mathrm{m}^{3}\right.$,
$41.8 \pm 4.7 \mu \mathrm{g} / \mathrm{m}^{3}, 26.8 \pm 2.7 \mu \mathrm{g} / \mathrm{m}^{3}$, respectively) and the lowest in M4 $\left(43.7 \pm 12.9 \mu \mathrm{g} / \mathrm{m}^{3}, 27.0\right.$ $\pm 4.0 \mu \mathrm{g} / \mathrm{m}^{3}, 19.1 \pm 1.9 \mu \mathrm{g} / \mathrm{m}^{3}$, respectively). All the MEs from M1 to M6 are air conditioned except M1 (see Section 2.1). The $8 \mathrm{~h}$ average outdoor $\mathrm{PM}_{10}, \mathrm{PM}_{2.5}$ and $\mathrm{PM}_{1.0}$ concentrations were $116 \pm 32.07 \mu \mathrm{g} / \mathrm{m}^{3}$, $60.7 \pm 12.2 \mu \mathrm{g} / \mathrm{m}^{3}$, and $50.06 \pm 11.6 \mu \mathrm{g} / \mathrm{m}^{3}$, respectively. The $I / O$ ratio of $\mathrm{PM}_{10}, \mathrm{PM}_{2.5}$ and $\mathrm{PM}_{1.0}$ in $\mathrm{M} 1$ as 1.93, 1.16 and 0.94, respectively, suggests the outdoor infiltration contributing to the all PM types. The results are in line with the study conducted by Hopke and Martinac (1998). They concluded that indoor PM concentration in naturally ventilated buildings will be higher compared with conditioned buildings, if located in a high outdoor air pollution area. Our results support these findings since concentration of all PM types in naturally ventilated environments (M7, M8 and M9) were higher than those in air conditioned MEs, due to higher penetration of outdoor pollution and the presence of indoor sources. Overall, the highest 8-hourly average concentrations of $\mathrm{PM}_{10}, \mathrm{PM}_{2.5}$ and $\mathrm{PM}_{1.0}$ were measured in M9 $\left(256.9 \pm 194.7 \mu \mathrm{g} / \mathrm{m}^{3}\right.$, $71.6 \pm 17.6 \mu \mathrm{g} / \mathrm{m}^{3}, \quad 43.6 \pm 6.4 \quad \mu \mathrm{g} / \mathrm{m}^{3}$, respectively) and M8 $\left(249.3 \pm 65.8 \mu \mathrm{g} / \mathrm{m}^{3}, 77.6\right.$ $\pm 27.4 \mu \mathrm{g} / \mathrm{m}^{3}, 50.2 \pm 22.1 \mu \mathrm{g} / \mathrm{m}^{3}$, respectively). The following two factors can explain these differences: outdoor infiltration which was common to all these three naturally ventilated MEs, and the indoor sources. $\mathrm{PM}_{10}$ was highest in M9 due to maximum number of occupant and their activities (Table 1). On the other hand, cooking and frying activities in M8 contributed to indoor $\mathrm{PM}_{2.5}$ and $\mathrm{PM}_{1.0}$ concentrations. The highest standard deviation $(\mathrm{SD} ; \pm 194.7)$ from $\mathrm{PM}_{10}$ mean was observed in $\mathrm{M} 9$, indicating large variations in activities of occupants. The M9 was fully occupied (20-25 persons) between 0900-1000 h (breakfast time), 1300-1600 h (lunch time) and 1600-1700 h (tea time) - this resulted in generation of highest $\mathrm{PM}_{10}$ concentration and consequently the largest SD. In case of $\mathrm{PM}_{2.5}$ and $\mathrm{PM}_{1.0}$, the highest SD $\left( \pm 27.4\right.$ and $\pm 22.1 \mu \mathrm{g} / \mathrm{m}^{3}$, 
Cite this article as: Goyal, R., Kumar, P., 2013. Indoor-outdoor concentrations of particulate matter in nine microenvironments of a mix-use commercial building in megacity Delhi. Air Quality, Atmosphere and Health 6, 747-757. http://dx.doi.org/10.1007/s11869-013-0212-0

respectively) was found in M8, indicating the variation in the intensity of emissions from sources (e.g. cooking and frying) at different hours (breakfast, lunch and tea) that have led to variations in their concentrations. Similarly, smoking activity takes place in M7 and M9 that have caused the higher SD in $\mathrm{PM}_{1.0}$ values.

SI Table S.2 shows the $24 \mathrm{~h}$ average values of $\mathrm{PM}_{10}, \mathrm{PM}_{2.5}$ and $\mathrm{PM}_{1.0}$. There are no IAQ standards or guidelines yet available for indoor PM concentrations in India. Comparison with other standards shows that the $24 \mathrm{~h}$ average $\mathrm{PM}_{10}$ concentrations in M8 $(198.3 \pm 68.87$ $\left.\mu \mathrm{g} / \mathrm{m}^{3}\right)$ and M9 $\left(204.8 \pm 155.5 \mu \mathrm{g} / \mathrm{m}^{3}\right)$ were found to be exceeding the USEPA $\left(150 \mu \mathrm{g} / \mathrm{m}^{3}\right)$ and WHO $\left(50 \mu \mathrm{g} / \mathrm{m}^{3}\right)$ guidance values. The mean $\mathrm{PM}_{10}$ concentrations in $\mathrm{M} 1(83.99 \pm 62.83$ $\left.\mu \mathrm{g} / \mathrm{m}^{3}\right), \quad$ M5 $\left(55.5 \pm 28.9 \mu \mathrm{g} / \mathrm{m}^{3}\right)$ and M7 $\left(91.2 \pm 22.8 \mu \mathrm{g} / \mathrm{m}^{3}\right)$ were below the USEPA standards, but exceeded the WHO guideline values by up to a factor of two. The case was identical for $24 \mathrm{~h}$ average $\mathrm{PM}_{2.5}$ concentrations in M8 $\left(60.95 \pm 13.1 \mu \mathrm{g} / \mathrm{m}^{3}\right)$ and M9 $(59.2 \pm 19.1$ $\left.\mu \mathrm{g} / \mathrm{m}^{3}\right)$, where these exceeded the WHO guideline value of $25 \mu \mathrm{g} / \mathrm{m}^{3}$. However, these are well within the USEPA standards (65 $\mu \mathrm{g} / \mathrm{m}^{3}$ ) for $24 \mathrm{~h}$ average $\mathrm{PM}_{2.5}$ exposure. In case of M1, M5, M6 and M7, $24 \mathrm{~h}$ average $\mathrm{PM}_{2.5}$ concentrations also exceeded the WHO guidelines. No such comparisons can be made for $\mathrm{PM}_{1.0}$ due to the unavailability of standards and guidelines.

The $24 \mathrm{~h}$ average ambient outdoor $\mathrm{PM}_{10}$ and $\mathrm{PM}_{2.5}$ concentrations were found to be $115.76 \pm 32.80 \mu \mathrm{g} / \mathrm{m}^{3}$ and $60.54 \pm 11.6 \mu \mathrm{g} / \mathrm{m}^{3}$, respectively; these exceed the permissible limits of 100 and $60 \mu \mathrm{g} / \mathrm{m}^{3}$ of National Ambient Air Quality Standards (NAAQS), India. These observations indicate that the studied building is located in an area having high outdoor particulate pollution. These high PM concentrations are generally caused by multiple sources such as biomass burning as in nearby slum area (NSR 2010; Kulshreshtha et al. 2008), resuspension of dust due to large commercial vehicles on adjacent road to the building (NSR 2010), exhausts from diesel engine trains (USEPA 2002) passing through the railway line located at the backside of studied building.

\subsection{I/O Relationship}

Figure 2 shows the outdoor concentrations of various $\mathrm{PM}$ fractions, along with the permissible limits of NAAQS for $\mathrm{PM}_{10}$ and $\mathrm{PM}_{2.5}$. The hourly average concentrations have been used to calculate the $I / O$ for different PM types in the studied MEs during the working hours (Figure 4). In case of the laboratories (M2-M4; except M1) and offices (M5-M6), the $I / O$ for various PM types was below 1.0. Conversely, this was greater than 1 in case of M7, M8 and M9 for all PM types, clearly indicating the influence of higher outdoor air flow rate (cfm/person; Table 1$)$ on the $I / O$ since this allowed more particles to enter the naturally ventilated MEs. However, in case of canteen (M9), where occupancy is much higher than other naturally ventilated MEs, influence of outdoor airflow rate on $I / O$ of PM was found to be overshadowed by the presence of indoor cooking sources and occupants activities.

Detailed inspection of the individual PM types suggests that the $I / O$ for $\mathrm{PM}_{10}$ was found to be varying from 0.37 to 3.1 in different MEs. The minimum (0.37) and maximum (3.1) $\mathrm{I} / \mathrm{O}$ were for M3 and M9, respectively (see Table 2). These are presumably due to the combined influence of ventilation types and indoor sources. Further, $I / O$ for M7 and M8 is 1.42 and 2.30 , respectively. In M3, occupant's entry is restricted and it is an air conditioned ME. Therefore, contribution from outdoor infiltration as well as from indoor activities is the lowest. In case of M7, M8 and M9, highest I/O (1.6, 3.02 and 3.1) were due to the presence of intense emissions from indoor sources as well as higher infiltration from outdoors through open windows, doors and ventilators (Goyal and Khare 2009). The 
Cite this article as: Goyal, R., Kumar, P., 2013. Indoor-outdoor concentrations of particulate matter in nine microenvironments of a mix-use commercial building in megacity Delhi. Air Quality, Atmosphere and Health 6, 747-757. http://dx.doi.org/10.1007/s11869-013-0212-0

results of numerous other studies on $I / O$ relationship also showed them varying from 0.5 to 2.0 in different indoor environments in the absence and presence of indoor sources, respectively (Morawska et al. 2001; Hussein et al. 2005). Of course occupants activities is another important factor that results in the resuspension of coarser particles, as is also reported by previous studies (Gomes et al. 2007; Hu et al. 2007).

The $I / O$ for $\mathrm{PM}_{2.5}$ and $\mathrm{PM}_{1.0}$ varied from 0.2 3.2 and $0.17-2.9$ in different MEs, respectively. Similar to the $I / O$ for the $\mathrm{PM}_{10}$, the $24 \mathrm{~h}$ average minimum $I / O(0.49$ and 0.57$)$ is found in $\mathrm{M} 2$ and $\mathrm{M} 3$ for both the $\mathrm{PM}_{2.5}$ and $\mathrm{PM}_{1.0}$. The maximum $I / O$ for $\mathrm{PM}_{2.5}(1.9)$ and $\mathrm{PM}_{1.0}$ (1.51) is found in M9 and M7, respectively. These observations suggest that the outdoor infiltration and the indoor sources are responsible for the higher $I / O$ in all the naturally ventilated MEs (M1, M7, M8 and M9).

The overall assessment of the $I / O$ ratio of different PM types indicates that the variations in $I / O$ are highest in case of $\mathrm{PM}_{10}$ compared with $\mathrm{PM}_{2.5}$ and $\mathrm{PM}_{1.0}$. Such a variation is expected given the more prominent settling and resuspension of $\mathrm{PM}_{10}$ compared with $\mathrm{PM}_{2.5}$ and $\mathrm{PM}_{1}$ (Thatcher and Layton 1995). In case of $\mathrm{PM}_{2.5}$ and $\mathrm{PM}_{1.0}$, the outdoor infiltration and building penetration factor may play more significant role in their $I / O$ ratios, depending on the ventilation type. A study by Dockery and Spengler (1981) on the $I / O$ relationship of $\mathrm{PM}_{2.5}$ indicated that the mean infiltration rate of outdoor fine particulates is $\sim 70 \%$ in case of naturally ventilated buildings and only $\sim 35$ $40 \%$ in case of fully air conditioned buildings. In line with the previous findings (Kulmala et al. 1999), the key parameters, which are believed to control the $I / O$ ratio of $P M$ in our case, are the air exchange rate between the indoor and the outdoor air, and the particle resuspension and settling.

\subsection{Proportion of PM Fractions in various MEs}

Figure 5 shows the proportion of different PM fractions in all the selected indoor MEs and during outdoor measurements. Together the $\mathrm{PM}_{2.5}(47 \%)$ and $\mathrm{PM}_{1.0}(37 \%)$ contributes $\sim 84 \%$ of the total $\mathrm{PM}_{10}$ concentration in outdoor ambient air, leaving only $16 \%$ for $\mathrm{PM}_{2.5-10}$. The higher fraction of smaller particles in the outdoor environment also indicates the dominance of contributions from biomass burning and fossil fuel combustion in road vehicles (Kumar et al. 2013b; NSR 2010). By looking at the indoor concentrations separately in different MEs, M7 shows nearly identical proportions of different PM fractions as were outdoors. The sum of $\mathrm{PM}_{2.5}$ and $\mathrm{PM}_{1.0}$ contributed $\sim 82 \%$ of total $\mathrm{PM}$ as opposed to $\sim 84 \%$ in outdoors - this can be expected given the frequent opening of doors/windows, allowing free movement of outdoor air into M7. In case of M1, M2, M8 and $\mathrm{M} 9, \mathrm{PM}_{2.5-10}$ contributes up to $56 \%$ of the total $\mathrm{PM}_{10}$. This indicates that the main source of $\mathrm{PM}_{2.5-10}$ indoors are human activities such as walking and cleaning that lead to resuspension of previously deposited larger sized particles. For instance, Almeida et al. (2011) and Majumdar et al. (2011) have carried out studies on school classrooms and found that concentration of $\mathrm{PM}_{2.5-10}$ increased by $50-100 \%$ in the classrooms due to physical activities of students, resulting in resuspension of particles deposited on classroom floors. Likewise, Gomes et al. (2007) have carried out an experimental chamber study to simulate the influence of occupant's walking on particle resuspension at various floor types. They found that aerodynamic disturbances dominate the particle resuspension behavior over the dust type, dust load and floor types; i.e. the forces working on different size of the particles is most important over the other factors, which may lead to their resuspension. Furthermore, a review by $\mathrm{Hu}$ et al. (2007) on particle resuspension concluded that mechanical, aerodynamic and electrostatic forces from 
Cite this article as: Goyal, R., Kumar, P., 2013. Indoor-outdoor concentrations of particulate matter in nine microenvironments of a mix-use commercial building in megacity Delhi. Air Quality, Atmosphere and Health 6, 747-757. http://dx.doi.org/10.1007/s11869-013-0212-0

human activity can lead to $100 \%$ resuspension of particles in indoor environments.

$\mathrm{PM}_{1.0}$ and $\mathrm{PM}_{2.5}$ contribute more than or equal to $90 \%$ of the total $\mathrm{PM}_{10}$ concentration in air conditioned MEs (M3, M4 and M6). These three MEs have comparatively restricted physical activities of occupants, except the computational and printing activities that may contribute to fine particles (Horemans and Van Grieken 2010). The doors remain closed most of the time in these MEs due to the operation of ACs fitted with filters, suggesting that the particles, which enter from outdoor air through ACs, will keep on accumulating in these MEs. A recent review by Chen and Zhao (2011) reported that the room occupancy level influences the concentrations of different sizes of particle in indoor environments. The occupants also have an effect on transport of particulates by controlling the ventilation system and/or opening the windows/doors, and their activities may result in particle generation, or re-suspension of previously deposit particles (Chen and Zhao 2011). In case of M3, M4 and M6, such activities are restricted that led to high concentration of $\mathrm{PM}_{2.5}$ and $\mathrm{PM}_{1.0}$ as oppose to $\mathrm{PM}_{10}$.

\subsection{Relationships between PM types and environmental/occupancy parameters}

Correlation analysis has been performed to understand the significance of relationship of different PM types with the environmental (temperature and $\mathrm{RH}$ ) and occupancy parameters $\left(\mathrm{CO}_{2}\right.$ concentration $)$. The twotailed Pearson's correlation matrix has been drawn and significance of correlations coefficients is tested for two significant levels, i.e. $99 \%$ and $95 \%$ confidence intervals (see SI Table S.3).

A positive correlation exists between $\mathrm{CO}_{2}$ and indoor PM concentrations; this correlation is more systematic and somewhat clearer for $\mathrm{PM}_{10}$, as shown in SI Table S.3. This indicates that sources of $\mathrm{PM}_{10}$ may be mostly the occupants and their activities (i.e. walking, cleaning, particle resuspension). These observations are in line with the findings of previous studies concluding that more intense occupant's activities result in higher the concentration of both $\mathrm{CO}_{2}$ and $\mathrm{PM}_{10}$ in indoor settings (Goyal and Khare 2009; Blondeau et al. 2005).

Correlations were established between the indoor temperatures and the PM types (SI Table S.3). Most of the mechanical ventilated MEs showed negative correlations for temperature as opposed to positive correlations seen in the case of natural ventilated MEs. Generally, when indoor temperature is high, particles tend to remain dry and hence contribute less towards increasing their sizes and mass concentrations (Massey et al. 2012). However, the variation in temperature during the experiments was modest (see Fig. 3) so the effect of temperature on PM type is hard to distinguish. Similar remains the case for relative humidity due to its small variations during the experiments (SI Table S.3).

Paired sample t-test has been performed for comparing the means of different size of PM concentration in different MEs. Unlike other MEs, the hourly concentration of $\mathrm{PM}_{10}$ in $\mathrm{M} 1$, M7 and M9 does not show the significant difference in their means at $95 \%$ confidence interval ( $p>0.05$ and $t<2.0$; SI Table S.4). Likewise in case of $\mathrm{PM}_{2.5}$, besides $\mathrm{M} 1$ and $\mathrm{M}$, no significant difference in the means of hourly concentrations are found $(p>0.05$ and $t<2.0)$ in rest of the MEs, presumably due to varying usage and occupants activities (SI Table S.5). There is however a significant difference $(p<0.05)$ between the means of hourly $\mathrm{PM}_{1.0}$ concentrations for all the MEs, except M7 and M9 (both affected by smoking), suggesting a common source for all them nsuch as the infiltrating from outdoors (see SI Table S.6).

\section{Summary and conclusions}


Cite this article as: Goyal, R., Kumar, P., 2013. Indoor-outdoor concentrations of particulate matter in nine microenvironments of a mix-use commercial building in megacity Delhi. Air Quality, Atmosphere and Health 6, 747-757. http://dx.doi.org/10.1007/s11869-013-0212-0

The IAQ monitoring was carried out inside a mixed use commercial building environment. As expected, the indoor concentration of $\mathrm{PM}_{10}$ during working hours $(0900-1800 \mathrm{~h})$ were found to be 6-10 times higher than those during non-working hours (remaining hours) in all the MEs, except M6 and M8, where the differences were only 2-3 times. Indoor $\mathrm{PM}_{2.5}$ and $\mathrm{PM}_{1.0}$ concentrations during the working hours were found to be $\sim 1.5-2$ times higher than those during the nonworking hours in most of the MEs. Indoor $\mathrm{PM}_{10}$ and $\mathrm{CO}_{2}$ concentration changed their values in tandem in the laboratories (M1 to M3) and offices (M5 and M6). However, this trend was not evident in MEs (M4, M8 and M9) influenced by other factors. For instance, poor ventilation conditions in M4 caused the higher $\mathrm{CO}_{2}$ concentrations. Intense but discontinuous activities of occupants in M8 and M9 were found to be responsible to generate variations in $\mathrm{PM}_{10}$ concentration which were not followed by the indoor $\mathrm{CO}_{2}$ concentrations.

The $24 \mathrm{~h}$ average data analysis of both outdoor and naturally ventilated indoor $\mathrm{PM}_{10}$ and $\mathrm{PM}_{2.5}$ concentrations indicated the violation of permissible limits for respective environments. However, their indoor concentrations in air conditioned MEs were within the prescribed limits of USEPA. No standards values are available for $\mathrm{PM}_{1.0}$ concentration for comparison purposes. The results clearly suggests that if a building is located in a mixed use polluted area (commercial, industrial, slum and transportation activities), the natural ventilated MEs are likely to experience higher infiltration of PM pollution compared with air conditioned, mechanical ventilated, MEs. This is also reflected by the $I / O$ relationships for all PM types. This was consistently less than 1 for mechanically ventilated MEs but much higher than 1 for naturally ventilated MEs (Figure 4). The highest variations in the $I / O$ relationship was found for the $\mathrm{PM}_{10}\left(0.37\right.$ to 3.1) and $\mathrm{PM}_{2.5}$ (0.2 to 3.2 ) - this was mainly due to the higher occupant activities leading to resuspension of coarse particles and the presence of indoor sources such as combustion and printing activities producing fine particles.

The proportion of different size fractions shows that $\mathrm{PM}_{2.5}$ and $\mathrm{PM}_{1.0}$ concentrations in outdoor air contribute to $\sim 84 \%$ of the total $\mathrm{PM}_{10}$ concentrations - similar proportions were found in reception (M7) area. However, these fractions change dramatically in some of the mechanically ventilated MEs (i.e. M3, M4 and M6) where sum of both $\mathrm{PM}_{1.0}$ and $\mathrm{PM}_{2.5}$ contribute over $90 \%$ of the total $\mathrm{PM}_{10}$ concentration - these were the MEs with ACs on and doors closed most of the time that did not allow the fine particles to escape once entered. Moreover, indoor sources such as computational and printing activities in these MEs exacerbated the levels of fine particles. Conversely, the MEs (M1, M2, M8 and M9) with greater physical activity of occupants, resulted in resuspension of previously deposited dust, showed larger fraction $(\geq 56 \%)$ of coarse particles $\left(\mathrm{PM}_{2.5-10}\right)$.

The statistical analysis of the data indicated a good correlation $(r>0.6)$ between indoor $\mathrm{PM}_{10}$, $\mathrm{PM}_{2.5}$ and $\mathrm{CO}_{2}$ concentrations and that the occupants and their activities are common indoor sources. The $\mathrm{PM}_{1.0}$ and $\mathrm{CO}_{2}$ were found to be poorly correlated, suggesting the dominance of outdoor infiltration on this relationship. Generally, indoor temperature and RH showed negative and positive correlations, respectively, with all the PM types. This relationship could not be verified due to small variations in the values of temperature and the $\mathrm{RH}$. Comparison of the results of the paired sample $t$-test shows that the means of indoor $\mathrm{PM}_{10}$ concentrations in different MEs are significantly different to those in outdoor environment. This strengthens our conclusion that occupants' movement is important for determining the $\mathrm{PM}_{10}$ concentrations. The means of indoor and outdoor $\mathrm{PM}_{2.5}$ and $\mathrm{PM}_{1.0}$ are comparable, especially in all mechanically ventilated MEs, 
Cite this article as: Goyal, R., Kumar, P., 2013. Indoor-outdoor concentrations of particulate matter in nine microenvironments of a mix-use commercial building in megacity Delhi. Air Quality, Atmosphere and Health 6, 747-757. http://dx.doi.org/10.1007/s11869-013-0212-0

substantiating our observations that ventilation type is important to determine the indoor concentrations of finer sized particles.

The study also has its explainable limitations. For instance, monitoring period was limited to one particular season due to practical constraints related to site access. Further data would have helped us to evaluate the influence of seasonal changes on the $I / O$ concentrations of PM. However given the uniqueness of the studied building in terms of its mixed use and location, the present study make a useful addition to the existing literature, in particular for a megacity like Delhi, where such measurements are yet under-represented.

The results of our study also have two important implications: one for the expousre assessment, and the other for future building design in megacities. Firstly, the derived $I / O$ relationship provides important information for making exposure estimates and developing efficient control strategies to reduce health risks in mixed-use, complex, building MEs such as those often forming part of non-domestic buildings in the polluted megacities. Secondly, it would be more appropriate to avoid natural ventilation, and use filter-fitted ACs in buildings that are situated in locations with significant outdoor PM pollution. If the latter option is not practically feasible, the use of recirculating air cleaners could be implemented to decrease PM levels and hence the associated exposure.

\section{Acknowledgements}

The authors thank the Director, CSIRNational Environmental Engineering Research Institute (NEERI) for providing support for present research. They would also like to thank the Environmental Engineering Laboratory of Indian Institute of Technology, Delhi, for providing the instrumental support and Ms. Papiya Mandal, Scientist, NEERI, Delhi Zonal Laboratory for providing the help during the experimental campaigns to carry out the monitoring work.

\section{References}

Almeida SM, Canha N, A. S, Carmo Freitas M, Pegas P, Alves C, Evtyugina M, Adrião C (2011) Children exposure to atmospheric particles in indoor of Lisbon primary schools. Atmos Environ 45:7594-7599

ASHRAE (2003). ASHRAE standards Ventilation for acceptable indoor air quality. American Society of Heating, Refrigerating and Air-Conditioning Engineers, Inc. ISSN 1041-2336

Baek S, Kim YS, Perry R (1997) Indoor air quality in homes, offices, and restaurants in Korean urban areas indoor/ outdoor relationships. Atmos Environ 31:529-544

Blondeau P, Lordache V, Popuard O, Genin D, Allard F (2005) Relationship between outdoor and indoor air quality in eight French schools. Indoor Air 15:2-12

Chaloulakou A, Mavroidis I, Douci A (2003) Indoor and outdoor carbon monoxide measurements at different microenvironments in the Athens area. Chemosphere 52 (6):1007-1019

Chen C, Zhao B (2011) Review of relationship between indoor and outdoor particles: $\mathrm{I} / \mathrm{O}$ ratio, infiltration factor and penetration factor. Atmospheric Environment 45:275-288

Chen C, Zhao B, Weschler C.J. (2012) Indoor exposure to "outdoor PM10": assessing its influence on the relationship between $\mathrm{PM}_{10}$ and short-term mortality in U.S. Cities", Epidemiology 23: 870878

Colbeck I, Nasir ZA, Ali Z (2010) Characteristics of indoor/outdoor particulate pollution in urban and rural residential environment of Pakistan. Indoor Air 20:40-51

Dockery DW, Spengler JD (1981) Indooroutdoor relationships of respirable 
Cite this article as: Goyal, R., Kumar, P., 2013. Indoor-outdoor concentrations of particulate matter in nine microenvironments of a mix-use commercial building in megacity Delhi. Air Quality, Atmosphere and Health 6, 747-757. http://dx.doi.org/10.1007/s11869-013-0212-0

sulfates and particles. Atmos Environ 15:335-343

Gomes C, Freihaut J, Bahnfleth W (2007) Resuspension of allergen-containing particles under mechanical and aerodynamic disturbances from human walking. Atmos Environ 41 (25):52575270

Goyal R, Khare M (2009) Indoor-outdoor concentrations of RSPM in classroom of a naturally ventilated school building near an urban traffic roadway. Atmos Environ 43:6026-6038

Goyal R, Khare M, Kumar P (2012) Indoor air quality: Current status, missing links and future road map for India. Journal of Civil and Environmental Engineering $2: 118$ http://dx.doi.org/110.4172/21654784X.1000118

Habil M, Massey D, Taneja A (2013) Exposure of children studying in schools of India to PM levels and metal contamination: sources and their identification. Air Quality, Atmosphere \& Health 6: 575587

Heal MR, Kumar P, Harrison RM (2012) Particles, air quality, policy and health. Chem Soc Rev 41:6606-6630. doi:10.1039/C2CS35076A

Hopke P, Martinac I (1998) Indoor climate and air quality. International Journal of Biometeorology 42:1-7

Horemans B, Van Grieken R (2010) Speciation and diurnal variation of thoracic, fine thoracic and sub-micrometer airborne particulate matter at naturally ventilated office environments. Atmos Environ 44:1497-1505

Hu B, Freihaut J, Bahnfleth W, Aumpansub P, Brandolyn $T$ (2007) Modeling the influence of human activity on particle resuspension and dispersion in a multizone indoor environment with HVAC system. ASCE Journal of Architectural Engineering 13:4-10
Hussein T, Glytsos T, Ondráček J, Dohányosová $\mathrm{P}$, Ždímal V, Hämeri K, Lazaridis M, Smolík J, Kulmala M (2006) Particle size characterization and emission rates during indoor activities in a house. Atmos Environ 40 (23):4285-4307. doi:10.1016/j.atmosenv.2006.03.053

Hussein T, Hameri K, Heikkinen MSA, Kulmala M (2005) Indoor and outdoor particle size characterization at a family house in Espoo-Finland. Atmos Environ 39:3697-3709

Jones NC, Thornton CA, Mark D, Harrison RM (2000) Indoor/outdoor relationships of particulate matter in domestic homes with roadside, urban and rural locations. Atmos Environ 34:2603-2612

Kleeman MJ, Schauer JJ, Cass GR (1999) Size and composition distribution of fine particulate matter emitted from wood burning, meat charbroiling, and cigarettes. Environmental Science \& Technology 33:3516-3523

Kukadia V, Palmer J (1998) The effect of external atmospheric pollution on indoor air quality: a pilot study. Energy and Buildings 27 (3):223-230

Kulmala M, Asmi A, Pirjola L (1999) Indoor air aerosol model: the effect of outdoor air, filtration and ventilation on indoor concentrations. Atmos Environ 33:2133-2144

Kulshreshtha P, M. K, Seetharaman P (2008) Indoor air quality assessment in and around urban slums of Delhi city, India. Indoor Air 18:488-498

Kumar P, Pirjola L, Ketzel M, Harrison RM (2013a) Nanoparticle emissions from 11 non-vehicle exhaust sources - a review. Atmos Environ 67:252-277

Kumar P, Jain S, Gurjar BR, Sharma P, Khare M, Morawska L, Britter R (2013b) New Directions: Can a "blue sky" return to Indian megacities? Atmos Environ 71:198-201. 
Cite this article as: Goyal, R., Kumar, P., 2013. Indoor-outdoor concentrations of particulate matter in nine microenvironments of a mix-use commercial building in megacity Delhi. Air Quality, Atmosphere and Health 6, 747-757. http://dx.doi.org/10.1007/s11869-013-0212-0

Kumar P, Morawska L (2013) EnergyPollution nexus for urban buildings. Environmental Science \& Technology 47:7591-7592.

Luoma M, Batterman SA (2001) Characterization of particulate emissions from occupant activities in offices. Indoor Air 11:35-48

Majumdar D, Gajghate DG, Pipalatkar P, Rao CVC (2011) Assessment of airborne fine particulate matter and particle size distribution in settled chalk dust during writing and dusting exercises in a classroom. Indoor and Built Environment 000:1-11, DOI: 10.1177/1420326X11419691. doi:10.1177/1420326x11419691

Massey D, Kulshrestha A, Masih J, Taneja A (2012) Seasonal trends of PM10, PM5.0, PM2.5 \& PM1.0 in indoor and outdoor environments of residential homes located in North-Central India. Building and Environment 47 (0):223231.

doi:10.1016/j.buildenv.2011.07.018

Massey D, Masih J, Kulshrestha A, Habil M, Taneja A (2009) Indoor/outdoor relationship of fine particles less than $2.5 \mathrm{~mm}$ (PM2.5) in residential homes locations in central Indian region. Building and Environment 44:20372045

Memarzadeh F (2009) Effect of reducing ventilation rate on indoor air quality and energy cost in laboratories. Journal of Chemical Health \& Safety 16:20-26

Miller SL, Nazaroff WW (2001) Environmental tobacco smoke particles in multizone indoor environments. Atmos Environ 35:2053-2067

Morawska L, He C, Hitchins J, Gilbert D, Parappukkaran S (2001) The relationship between indoor and outdoor airborne particles in the residential environment. Atmos Environ 35:3463-3473
Morawska L, He C, Hitchins J, Mengersen K, Gilbert D (2003) Characteristic of particle number and mass concentrations in residential houses in Brisbane, Australia. Atmos Environ 37:4195-4203

NSR (2010) Air quality monitoring, emission inventory and source apportionment study for Indian cities. National Science Report of Central Pollution Control Board, Delhi

Ott WR, Siegmann HC (2006) Using multiple continuous fine particle monitors to characterize tobacco, incense, candle, cooking, wood burning, and vehicular sources in indoor, outdoor, and intransit settings. Atmos Environ 40: 821843

Polichetti G, Cocco S, Spinali A, Trimarco V, Nunziata A (2009) Effects of particulate matter $\left(\mathrm{PM}_{10}, \mathrm{PM}_{2.5}\right.$ and $\mathrm{PM}_{1}$ ) on the cardiovascular system. Toxicology 261: 1-8

Pope III CA, Dockery DW (2006) Health effects of fine particulate air pollution: Lines that connect. Journal of Air \& Waste Management Association 56:707-742

Raunemaa T, Kulmala M, Saari H, Olin M, Kulmala MH (1989) Indoor air aerosol model: transport indoors and deposition of fine and coarse particles. Aerosol Sci Technol 11:11-25

Santos JM, Mavroidis I, N.C. RJ, Pagel EC (2011) Experimental investigation of outdoor and indoor mean concentrations and concentration fluctuations of pollutants. Atmos Environ 45:6534-6545

Thatcher TL, Layton DW (1995) Deposition, resuspension, and penetration of particles within a residence. Atmos Environ 29:1487-1497

USEPA (2002) Health assessment document for diesel engine exhaust. National Center for Environmental Assessment Office of Research and Development 
Cite this article as: Goyal, R., Kumar, P., 2013. Indoor-outdoor concentrations of particulate matter in nine microenvironments of a mix-use commercial building in megacity Delhi. Air Quality, Atmosphere and Health 6, 747-757. http://dx.doi.org/10.1007/s11869-013-0212-0

Washington, DC EPA/600/8-90/057F

Available from http://wwwepagov/iris

Wallace L (1996) Indoor particles: A review. Journal of the Air Waste Management Association 46:98-126

Yamamoto N, Shendell DG, Winer AM, Zhang J (2010) Residential air exchange rates in three major US metropolitan areas: results from the relationship among indoor, outdoor, and personal air study 1999-2001. Indoor Air 20:85-90

Zhou B, Zhao B, Guo X, Chen R, Kan H (2013) Investigating the geographical heterogeneity in PM10-mortality associations in the China Air Pollution and Health Effects Study (CAPES): A potential role of indoor exposure to $\mathrm{PM}_{10}$ of outdoor origin. Atmospheric Environment 75: 217-223 
Cite this article as: Goyal, R., Kumar, P., 2013. Indoor-outdoor concentrations of particulate matter in nine microenvironments of a mix-use commercial building in megacity Delhi. Air Quality, Atmosphere and Health 6, 747-757. http://dx.doi.org/10.1007/s11869-013-0212-0

\section{List of tables}

Table 1. Details of various parameters of selected MEs for the IAQ monitoring in this study.

${ }^{a} \mathrm{AC}$ is switch-off for most of the time and windows remained open during experiments.

\begin{tabular}{|c|c|c|c|c|c|}
\hline $\begin{array}{l}\text { Name of microenvironment } \\
\text { (Abbreviation) }\end{array}$ & $\begin{array}{l}\text { Volume } \\
\left(\mathrm{m}^{3}\right)\end{array}$ & $\begin{array}{l}\text { Ventilation } \\
\text { type }\end{array}$ & $\begin{array}{l}\text { Monitoring } \\
\text { duration } \\
\text { (hours) }\end{array}$ & $\begin{array}{l}\text { Occupancy } \\
\text { level }^{\mathrm{b}}\end{array}$ & $\begin{array}{l}\text { Ventilation flow rate } \\
\text { (cfm/person) } \\
\text { minimum-maximum } \\
\text { (average) }\end{array}$ \\
\hline Chemical Lab (M1) & 226.6 & $\begin{array}{l}\text { Mechanical } \\
\text { /Natural }^{\mathrm{a}}\end{array}$ & 24 & $3-4$ & $184-245(214)$ \\
\hline Instrumentation Lab (M2) & 226.6 & Mechanical & 24 & $2-3$ & $180-271(225)$ \\
\hline Microbiology Lab (M3) & 161.8 & Mechanical & 24 & $2-3$ & $179-268(224)$ \\
\hline Computational Lab (M4) & 189.0 & Mechanical & 24 & $5-10$ & $22-44(33)$ \\
\hline Admin Office (M5) & 291.37 & Mechanical & 24 & $8-15$ & $14-26(20)$ \\
\hline Scientist Room (M6) & 189.0 & Mechanical & 24 & $3-8$ & $48-127(87)$ \\
\hline Reception (M7) & 269.5 & Natural & 8 & $2-3$ & $301-452(377)$ \\
\hline Kitchen (M8) & 105.0 & Natural & 24 & $2-4$ & $135-270(203)$ \\
\hline Canteen (M9) & 220.5 & Natural & 8 & $20-25$ & $21-27(24)$ \\
\hline
\end{tabular}

${ }^{b}$ Range of the maximum number of people present at one time during the working hours.

${ }^{c}$ Represents the fresh outdoor air available to each person inside the respective microenvironments the details of $\mathrm{cfm}$ estimation method are available in SI Section S1. ASHRAE standards recommend the minimum required ventilation rate at breathing zone for office building and reception area as 5 $\mathrm{cfm} /$ person, computational and science lab as $10 \mathrm{cfm} /$ person, and kitchen area as $75 \mathrm{cfm} /$ person (ASHRAE, 2003). 
Cite this article as: Goyal, R., Kumar, P., 2013. Indoor-outdoor concentrations of particulate matter in nine microenvironments of a mix-use commercial building in megacity Delhi. Air Quality, Atmosphere and Health 6, 747-757. http://dx.doi.org/10.1007/s11869-013-0212-0

Table 2. I/O relationships of different PM types in studied MEs.

\begin{tabular}{|c|c|c|c|c|c|c|c|c|c|}
\hline \multirow[t]{2}{*}{ MEs } & \multicolumn{3}{|c|}{$I / O \mathrm{PM}_{10}$} & \multicolumn{3}{|c|}{$I / O \mathbf{P M}_{2.5}$} & \multicolumn{3}{|c|}{$I / O \mathrm{PM}_{1.0}$} \\
\hline & $\begin{array}{l}\text { Mea } \\
\text { n }\end{array}$ & SD & Range & Mean & SD & Range & Mean & SD & Range \\
\hline M1 & 1.93 & 1.14 & $1.5-2.4$ & 1.16 & 0.63 & $\begin{array}{l}1.05-1.4 \\
4\end{array}$ & 0.94 & 0.37 & $\begin{array}{l}0.76-1.2 \\
3\end{array}$ \\
\hline M2 & 1.1 & 0.79 & $0.9-1.08$ & 0.74 & 1.05 & $\begin{array}{l}0.68-0.8 \\
6\end{array}$ & 0.63 & 1.05 & $\begin{array}{l}0.56-0.7 \\
8\end{array}$ \\
\hline M3 & 0.62 & 0.71 & $\begin{array}{l}0.61-0.7 \\
1\end{array}$ & 0.75 & 1.27 & $0.8-1.1$ & 0.64 & 0.98 & $\begin{array}{l}0.75-0.9 \\
2\end{array}$ \\
\hline M4 & 0.53 & 0.45 & $0.5-0.62$ & 0.75 & 0.54 & $\begin{array}{l}0.73-0.9 \\
4\end{array}$ & 0.67 & 0.26 & $\begin{array}{l}0.56-0.9 \\
0\end{array}$ \\
\hline M5 & 0.99 & 0.73 & $\begin{array}{l}0.83-1.0 \\
7\end{array}$ & 0.81 & 0.61 & $\begin{array}{l}0.78-0.9 \\
2\end{array}$ & 0.66 & 0.43 & $\begin{array}{l}0.61-0.7 \\
8\end{array}$ \\
\hline M6 & 0.71 & 0.31 & $0.49-0.85$ & 0.81 & 0.52 & $\begin{array}{l}0.76-0.9 \\
9\end{array}$ & 0.7 & 0.55 & $\begin{array}{l}0.67-0.8 \\
3\end{array}$ \\
\hline M7 & 1.6 & 1.2 & $1.3-1.44$ & 1.65 & 2.73 & $\begin{array}{l}0.13-2.7 \\
8\end{array}$ & 1.51 & 1.86 & $1.4-1.57$ \\
\hline M8 & 3.02 & 2.3 & $2.5-3.4$ & 2.15 & 3.7 & $1.92-2.5$ & 1.33 & 3.07 & $1.36-2.07$ \\
\hline M9 & 3.1 & 6.8 & $2.89-5.65$ & 1.98 & 2.3 & $2.25-2.5$ & 1.47 & 0.89 & $1.44-1.87$ \\
\hline
\end{tabular}


Cite this article as: Goyal, R., Kumar, P., 2013. Indoor-outdoor concentrations of particulate matter in nine microenvironments of a mix-use commercial building in megacity Delhi. Air Quality, Atmosphere and Health 6, 747-757. http://dx.doi.org/10.1007/s11869-013-0212-0

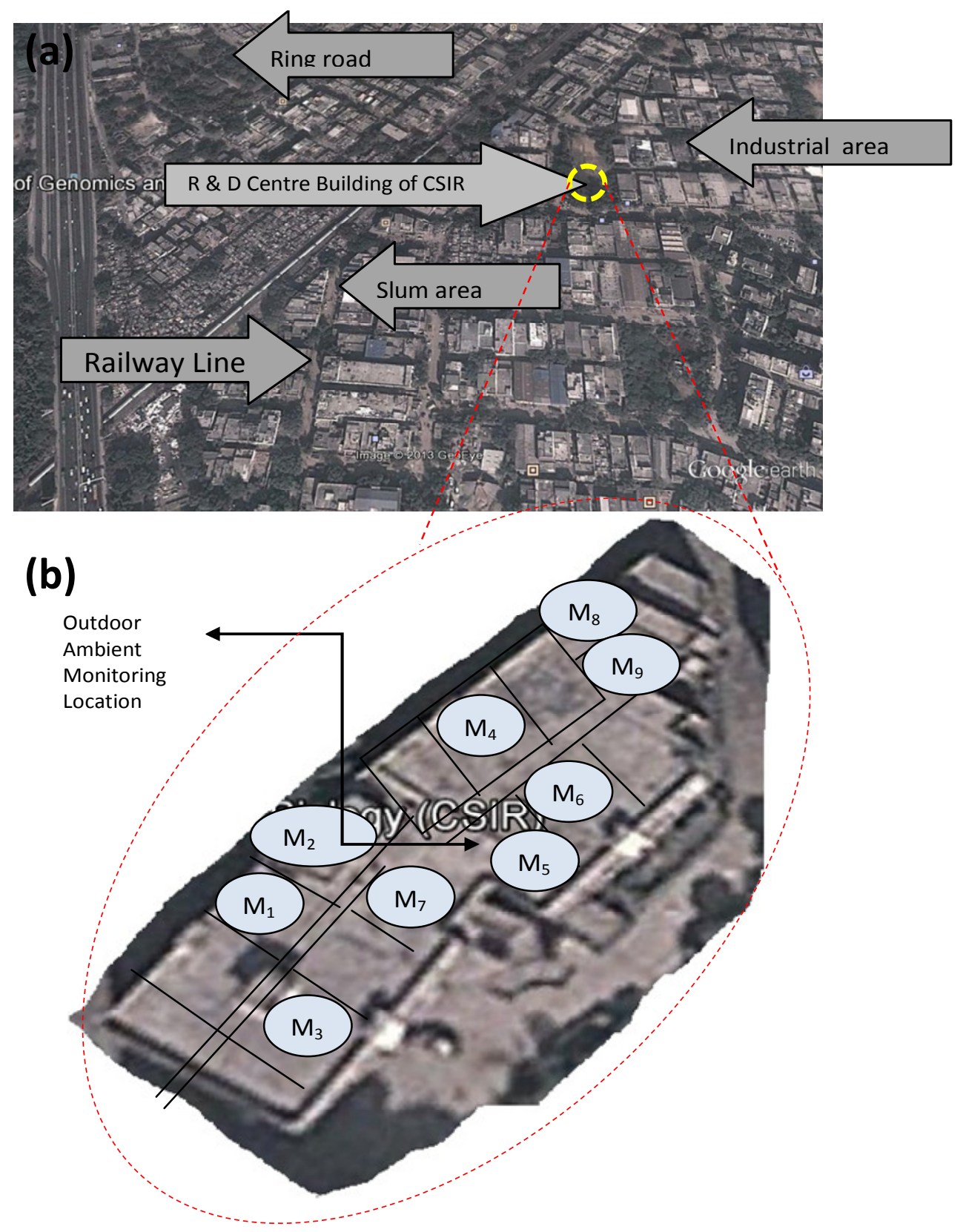

Figure 1. Aerial view of the building showing (a) its location in mixed use area, and (b) indoor-outdoor air monitoring locations. IAQ monitoring was carried out in all these MEs, as detailed in Section 2.2. 
Cite this article as: Goyal, R., Kumar, P., 2013. Indoor-outdoor concentrations of particulate matter in nine microenvironments of a mix-use commercial building in megacity Delhi. Air Quality, Atmosphere and Health 6, 747-757. http://dx.doi.org/10.1007/s11869-013-0212-0

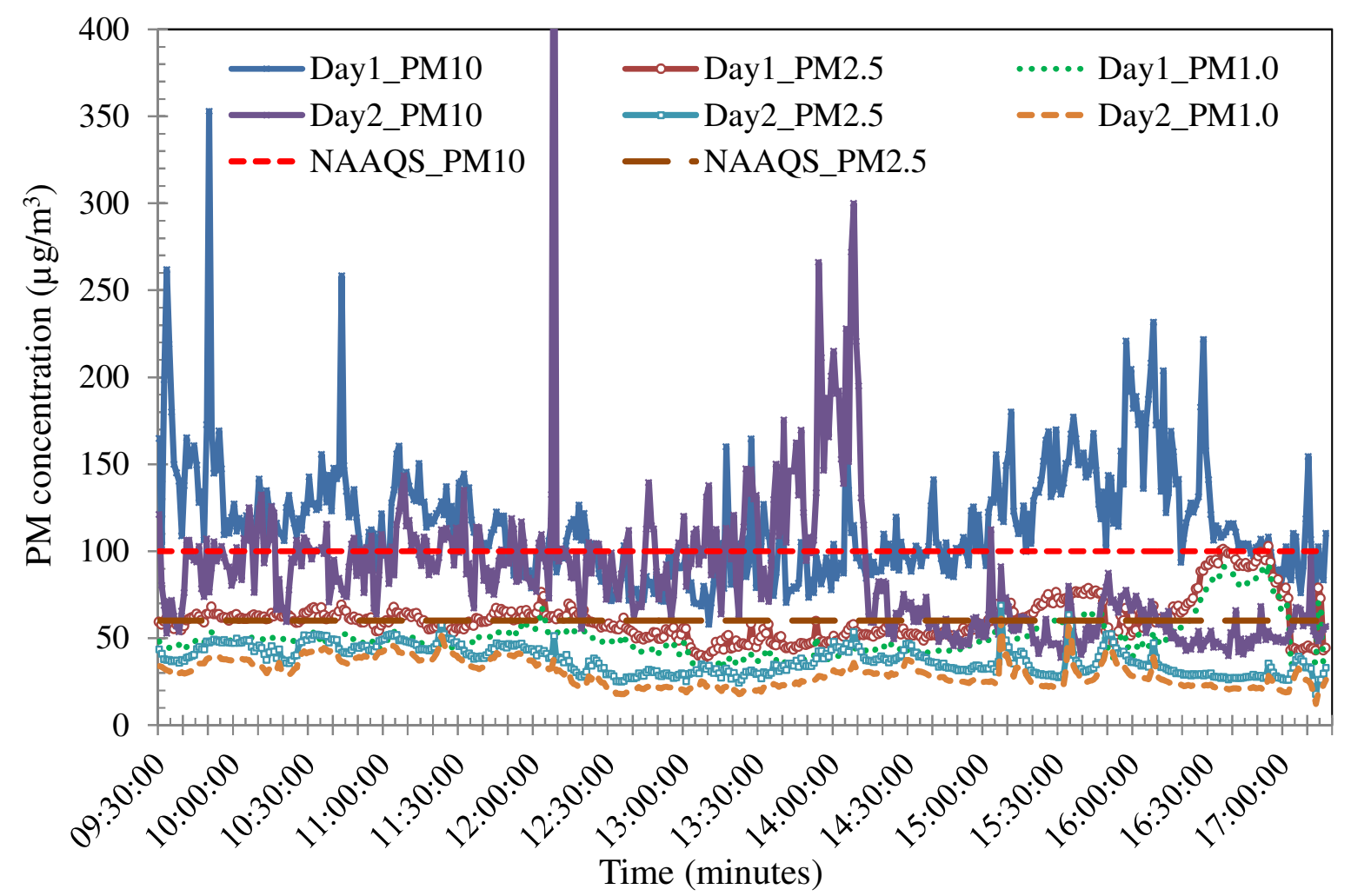

Figure 2. Outdoor PM concentration profile showing the number of exceedences over the NAAQS permissible limits. 
Cite this article as: Goyal, R., Kumar, P., 2013. Indoor-outdoor concentrations of particulate matter in nine microenvironments of a mix-use commercial building in megacity Delhi. Air Quality, Atmosphere and Health 6, 747-757. http://dx.doi.org/10.1007/s11869-013-0212-0

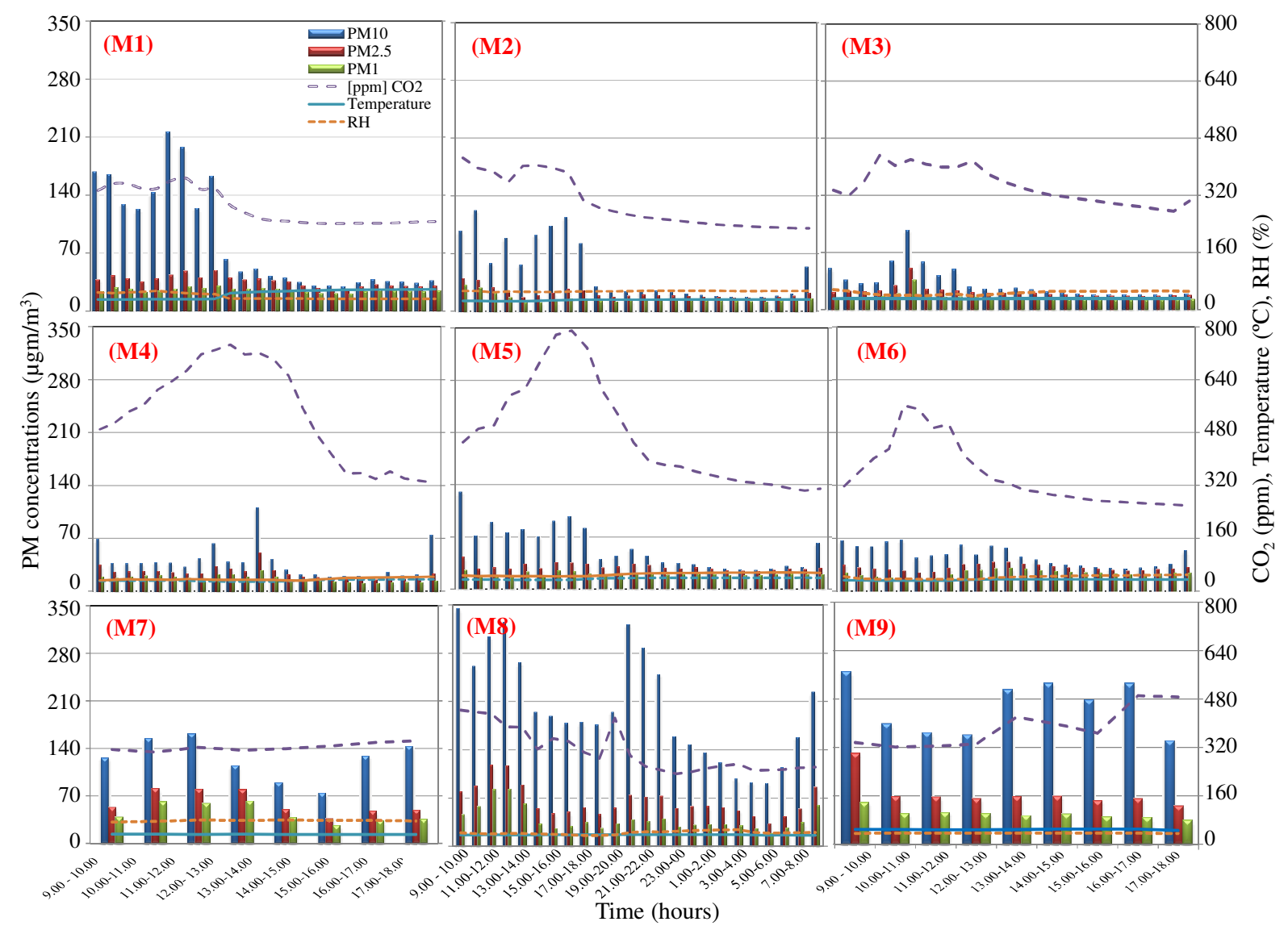

Figure 3. Diurnal varaition of $\mathrm{PM}$, indoor $\mathrm{CO}_{2}$ concentrations, and environmental parameters for the studied MEs. Note that the $x$-axis of the figures in rows 1 and 2 shows hourly PM concentrations over the period of 24 hours, starting from 0900-1000 h (previous day) to $0800-0900 \mathrm{~h}$ (next day). 
Cite this article as: Goyal, R., Kumar, P., 2013. Indoor-outdoor concentrations of particulate matter in nine microenvironments of a mix-use commercial building in megacity Delhi. Air Quality, Atmosphere and Health 6, 747-757. http://dx.doi.org/10.1007/s11869-013-0212-0

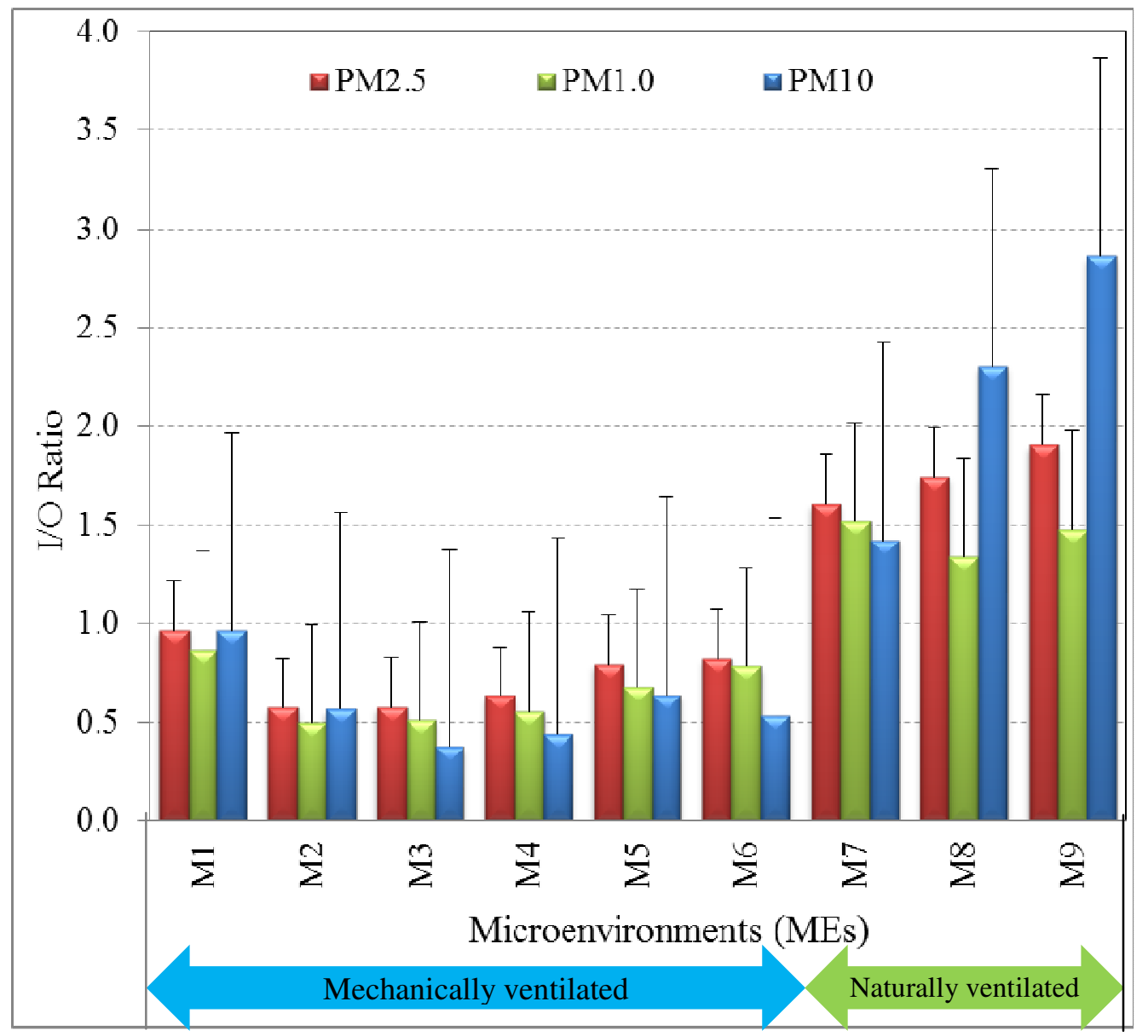

Figure 4. $\mathrm{I} / \mathrm{O}$ ratio of $\mathrm{PM}_{10}, \mathrm{PM}_{2.5}$ and $\mathrm{PM}_{1.0}$ in different MEs. 
Cite this article as: Goyal, R., Kumar, P., 2013. Indoor-outdoor concentrations of particulate matter in nine microenvironments of a mix-use commercial building in megacity Delhi. Air Quality, Atmosphere and Health 6, 747-757. http://dx.doi.org/10.1007/s11869-013-0212-0

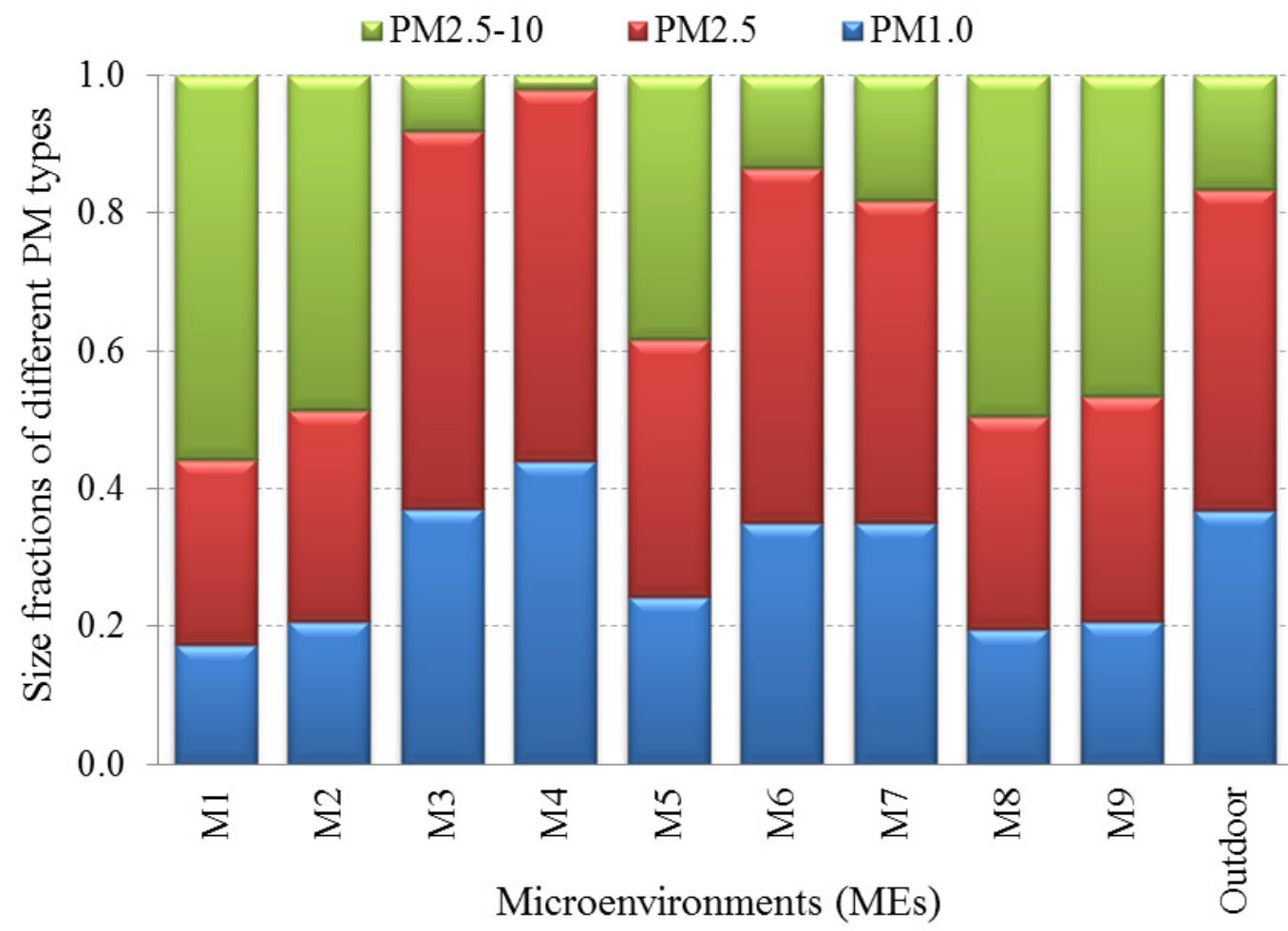

Figure 5. Proportion of PM concentrations in various size ranges in all the MEs and outdoor environment. 